\title{
PERANCANGAN SISTEM FORMULIR PELAYANAN KEDUKAAN ONLINE MENGGUNAKAN METODE WEB BASE ENGINEERING PADA PT. ABADI CAHAYA UNIVERSAL (RUMAH DUKA ABADI) JAKARTA
}

\author{
Jaka Sutresna \\ Fakultas Teknik, Prodi Teknik Informatika, Universitas Pamulang \\ J1. Surya Kencana No. 1, Pamulang, Tanggerang Selatan-Indonesia \\ email: jakasutrisna@gmail.com
}

\begin{abstract}
ABSTRAK
Pelayanan kedukaan di Rumah Duka Abadi saat ini masih menggunakan sistem formulir manual, dan proses booking tempat pun masih manual, penulis melakukan penelitian untuk pembuatan sistem formulir pelayanan yang berbasis komputer yang terhubung dengan internet, dengan adanya sistem ini maka setiap sales yang tersebar di beberapa rumah sakit di jakarta tidak perlu bolak-balik ke kantor untuk mengurus data maupun pemesanan tempat. Dalam pembuatan Sistem Formulir Pelayanan Kedukaan Online ini metode yang digunakan dalam pengembangannya adalah metode Web Based Engineering, karena memiliki keunggulan dibandingkan model-model lainnya, dengan metode ini menghasilkan sistem yang efisien dan lebih mudah terkontrol. Hasil dari penelitian ini diharapkan Sistem Formulir Pelayanan Kedukaan Online yang telah dibuat dapat membantu dalam kegiatan transaksi pelayanan terhadap customer yang membutuhkan jasa rumah duka ini menjadi lebih baik lagi. Sistem pada penelitian ini di implementasikan menggunakan bahasa pemrograman PHP dan Apache sebagai web server-nya, serta manajemen sistem database menggunakan MySql.
\end{abstract}

Kata Kunci : Sistem Formulir Pelayanan Kedukaan Online, UML, PHP, MySQL, Website, Web Engineering.

\section{PENDAHULUAN \\ Latar Belakang}

PT. Abadi Cahaya Universal yang merupakan perusahaan yang mengelola Rumah Duka Abadi dalam operasional dan manajemen pelayanan di Rumah Duka Abadi. Rumah Duka Abadi sendiri merupakan sebuah yayasan yang bergerak dalam bidang pelayanan berupa kedukaan serta penyedia jasa penggunaan kendaraan untuk jemput jenazah maupun antar jenazah, jasa memandikan jenazah dan kremasi jenazah. Di dalam upaya meningkatkan mutu dan pelayanan terhadap customer yang berkualitas, maka Rumah Duka Abadi diperlukan peningkatan kualitas dan kuantitas dari sarana dan prasarana, tetapi peningkatan jumlah sarana tidak sebanding dengan banyaknya karyawan yang ada, sehingga waktu yang dialokasikan oleh seorang karyawan terutama bagian sales marketting semakin terbatas, serta untuk melakukan transaksi penjualan produk (penjualan peti dan penyewaan ruangan) serta pencatatan administrasi pendataan customer yang masih manual yaitu melakukan pengisian formulir pelayanan harus datang ke kantor dan dilakukan dengan cara tulis tangan serta ada juga yang dicatat dibuku catatan, sehingga akan kesulitan untuk membuat laporan bulanan atau laporan tahunan dikarenakan tempat penyimpanan data yang sering berceceran. Dengan demikian secara otomatis peningkatan kualitas pelayanan yang diinginkan tidak akan tercapai. Kurangnya interaksi antara sales marketting dan customer serta keterbatasan waktu menjadi kendala utama.

Untuk itu perlu ada cara lain yang dapat menangani kondisi tadi. Salah satunya perlu dibuatnya sebuah sistem yang dapat mengakomodir dalam kegiatan pelayanan customer baik secara offline yaitu customer datang langsung ke kantor untuk melakukan proses pemesanan, mengisi formulir serta melakukan transaksi pembayaran, atau pelayanan secara online yaitu dengan memanfaatkan teknologi jaringan internet. Pelayanan yang menggunakan teknologi internet ini dapat memudahkan dalam melakukan pengisian formulir pelayanan yang dapat dilakukan oleh Sales Marketting atau oleh customer juga. Jadi salah satu unsur utama yang harus ada dalam pelayanan menggunakan internet adalah adanya interaksi antara sales marketting dengan customer. Dalam interaksi ini, customer maupun 
calon customer bisa bertanya langsung mengenai fasilitas maupun yang lainnya kepada staff pelayanan tanpa harus datang ke lokasi pelayanan yaitu bisa dilakukan secara online.

Dalam pembuatan Sistem Formulir Pelayanan Kedukaan Online ini metode yang digunakan dalam pengembangannya adalah metode Web Based Engineering, karena memiliki kelebihan atau keunggulan dibandingkan modelmodel lainnya, dengan metode ini menghasilkan sistem yang efisien dan lebih mudah terkontrol.

\section{Rumusan Masalah}

Adapun masalah yang akan dibahas penulis penelitian dalam pembuatan tesis ini adalah sebagai berikut:

1) Bagaimana melakukan perancangan untuk membangan Sistem Formulir Pelayanan Kedukaan Online yang dapat memudahkan transaksi dan operasional!

2) Bagaimana membangun sistem penyimpanan data yang dapat mengolah data supaya tidak berceceran dan tidak terjadi kehilangan data!

3) Bagaimana membangun sistem yang bisa membuat laporan bulanan maupun laporan tahunan!

\section{Batasan Masalah}

Dalam penulisan tesis ini, penulis membatasi masalah yang akan penulis bahas, yaitu sebagai berikut :

1) Sistem yang dibahas dalam penulisan tesis ini adalah Sistem Formulir Pelayanan Kedukaan Online yang berbasis web.

2) Sistem ini dibuat menggunakan bahasa pemrograman HTML dan PHP serta MySQL sebagai tempat penyimpanan databasenya.

3) Metode pengembangan yang digunakan dalam perancangan Sistem Formulir Pelayanan Kedukaan Online ini adalah Metode Web Base Engineering.

\section{Tujuan}

Tujuan yang ingin dicapai di dalam penulisan tesis ini adalah sebagai berikut :

1) Untuk mengetahui sistem yang berjalan saat ini tentang pelayanan kedukaan di Rumah Duka Abadi,

2) Untuk membangun sebuah Sistem Formulir Pelayanan Kedukaan Online yang dinamis agar mempermudah dalam melaksanakan kegiatan pelayanan terhadap customer dan memudahkan dalam melakukan manajemen database.

\section{Manfaat}

Penelitian ini diharapkan akan memberikan manfaat yang baik untuk penulis, perusahaan maupun akademis.

a. Bagi penulis

Menambah wawasan, pengalaman dan kreativitas penulis dalam pembelajaran mengenai teknik mendesain, mengelola dan mengembangkan website sehingga dapat mengetahui sampai dimana kemampuan penulis dalam menyerap ilmu pengetahuan yang diperoleh dalam perkuliahan.

b. Bagi perusahaan

- Diharapkan dapat memberikan solusi dan kemudahan yang tersaji di dalam satu sistem dan dapat memberikan peningkatan pelayanan untuk menjadi lebih baik lagi.

- Sebagai masukan, memberikan sumbangan pemikiran dan pertimbangan untuk mengoptimalkan tujuan perusahaan dalam menyelesaikan masalah sehingga memberikan acuan yang baik.

c. Bagi Akademik

Diharapkan penelitian yang telah dibuat ini dapat dijadikan rujukan bagi peneliti yang lain dalam mengembangkan pengetahuannya, dan berguna juga untuk menjadi referensi bagi mahasiswa yang melakukan kajian terhadap pembangunan sistem aplikasi terkait transaksi jual beli dan inventarisasi.

\section{LANDASAN TEORI Pengertian Penjualan}

Penjualan adalah sebuah usaha atau langkah konkrit yang dilakukan untuk memindahkan suatu produk, baik itu berupa barang atau jasa, dari produsen kepada konsumen sebagai sasarannya. Tujuan utama penjualan yaitu mendatangkan keuntungan atau laba dari produk atau barang yang dihasilkan produsennya dengan pengelolaan yang baik. Dalam pelaksanaannya, penjualan sendiri tak akan dapat dilakukan tanpa adanya pelaku yang bekerja didalamnya seperti agen, pedangang, dan tenaga pemasaran.

\section{Pengertian Formulir}


Formulir adalah lembaran kartu/kertas dengan ukuran tertentu yang didalamnya terdapat data/informasi yang bersifat tetap dan juga bagian lain yang diisi dengan bagian yang tidak tetap

Dalam hal Administrasi dan Keuangan Perusahaan, formulir berfungsi sebagai dokumen yang memiliki kekuatan untuk membantu pihakpihak yang terlibat dalam menetapkan tanggung jawab dan merekam transaksi bisnis perusahaan.

\section{Pengertian Pelayanan}

Pelayanan menurut Kamus Besar Bahasa Indonesia (KBBI) adalah sebagai suatu usaha untuk membantu menyiapkan atau mengurus apa yang diperlukan orang lain. Sedangkan menurut Moenir (2010 : 26) pelayanan adalah kegiatan yang dilakukan oleh seseorang atau sekelompok orang dengan landasan faktor materi melalui sistem, prosedur dan metode tertentu dalam rangka usaha memenuhi kepentingan orang lain sesuai dengan haknya.

\section{Pengertian Arsip}

Pengertian arsip bukan hanya berarti kertas saja, tetapi dapat berarti naskah, buku, foto, film, mikro film, rekaman suara, gambar peta, gambar bagan dan dokumen-dokumen lain dalam segala macam bentuk dan sifatnya, asli atau salinan serta dengan segala macam bentuk dan ciptaannya, dan yang dihasilkan atau diterima oleh sesuatu organisasi/badan, sebagai bukti dari tujuan organisasi, fungsi, prosedur pekerjaan, atau kegiatan pemerintah lainnya atau karena pentingnya informasi yang terkandung didalamnya (Sedarmayanti, 2008).

\section{Pengertian Web Engineering}

Sebuah aplikasi web adalah sebuah sistem perangkat lunak berdasarkan teknologi dan standar dari World Wide Web Consortium (W3C) seperti konten dan layanan melalui antar muka pengguna browser web. Web engineering adalah penerapan sistematis dan kuantitatif pendekatan (konsep, metode, teknik, alat) untuk biaya efektif analisa kebutuhan, desain, implementasi, pengujian, pengoperasian, dan pemeliharaan berkualitas aplikasi web.

Web Engineering adalah suatu model rekayasa perangkat lunak yang digunakan untuk pengembangan aplikasi-aplikasi web yang berkualitas tinggi yang memiliki konsep dan prinsip mendasar dari rekayasa perangkat lunak (software engineering).

\section{METODE PENELITIAN}

\section{Metode Pengembangan Sistem}

Untuk pengembangan sistem Formulir Pelayanan kedukaan online ini metode pengembangannya menggunakan metode web engineering, karena metode ini memberikan ide bagi penulis maupun user tentang cara sistem akan berfungsi dan yang akan dikembangkan. Metode web engineering terdapat 5 ( lima ) tahapan untuk dapat mengembangkan suatu perangkat lunak seperti gambar dibawah ini :

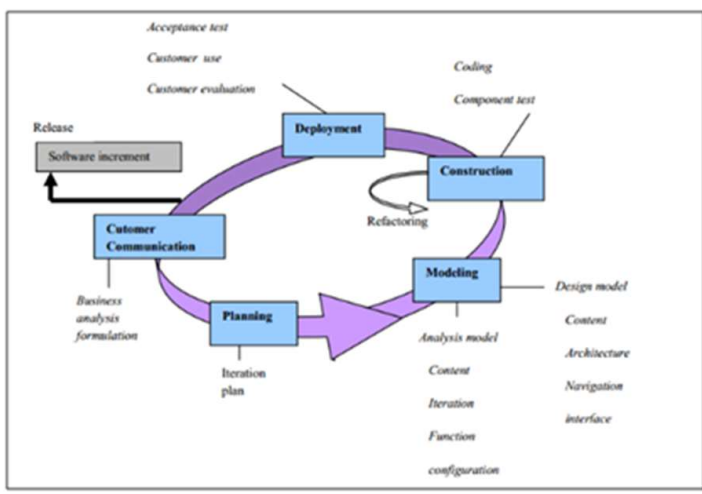

Gambar 3.1 Tahapan-tahapan Proses Web Engineering

Tahapan tersebut antara lain :

1. Customer communication

Komunikasi dalam hal ini terutama terkonsentrasi pada 2 hal, analisa bisnis dan perumusan. Analisa bisnis akan mendefinisikan hal-hal apa saja yang akan termuat di dalam aplikasi web, misalnya pengguna web yang akan dibangun, perubahan potensial dalam lingkungan bisnis, integrasi antara web yang akan dibangun dengan situasi bisnis perusahaan, maupun database perusahaan. Perumusan adalah pengumpulan informasi tentang hal-hal yang akan dimuat dalam web yang melibatkan semua calon pengguna.

2. Planning

Perencanaan proyek pengembangan aplikasi web kemudian ditentukan, perencanaan akan terdiri dari pendefinisian pekerjaan dan target waktu atas pekerjaan maupun sub pekerjaan yang ditentukan tersebut.

\section{Modeling}

Tujuan dari aktivitas ini adalah untuk menjelaskan hal-hal apa saja yang memang diperlukan / dibutuhkan pada aplikasi yang akan dibangun dan solusi yang ditawarkan yang diharapkan dapat menjawab apa yang 
tersirat dari hasil-hasil analisa dan pengumpulan data.

4. Construction

Pembangunan aplikasi web memadukan antara perkembangan teknologi dengan tools pengembangan web yang telah ada, artinya memilih tools yang efektif namun tetap dapat menyesuaikan dengan teknologi yang berkembang saat ini.

5. Deployment

Aplikasi web diciptakan untuk dapat berguna bagi kebutuhan pekerjaan, dapat dioperasikan oleh end-user, dan kemudian dilakukan evaluasi secara berkala, memberi masukan-masukan kepada team pengembang dan apabila diperlukan akan dilakukan modifikasi pada aplikasi web tersebut. Alasan penyusun menggunakan metode web engineering ini, karena metode ini cukup efektif sebagai paradigma dalam rekayasa perangkat lunak, karena mendapatkan kebutuhan dan aturan yang jelas yang disetujui oleh pelanggan, dalam pembuatan perangkat lunak bisa dilakukan secara cepat dan memungkinkan untuk merubah kembali perangkat lunak agar sesuai dengan kebutuhan pelanggan.

\section{HASIL DAN PEMBAHASAN Use Case Diagram}

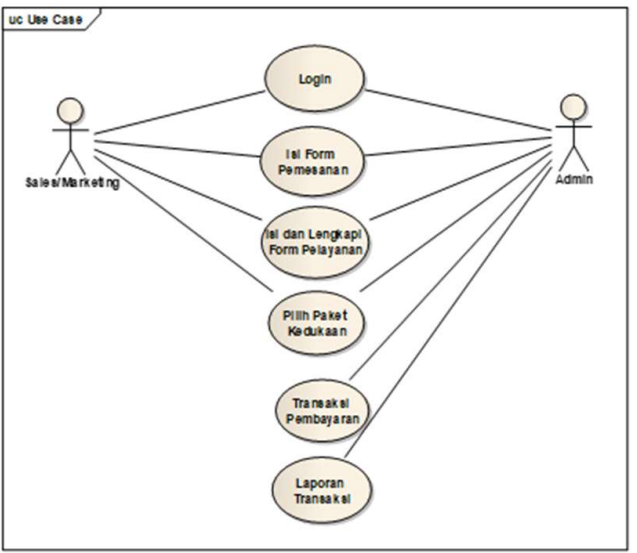

Gambar 4.1. Use Case Diagram

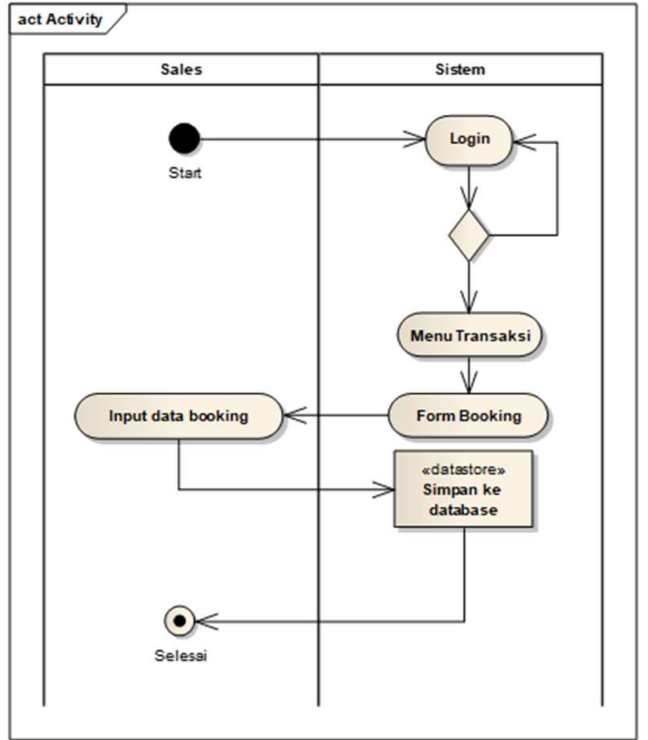

Gambar 4.2. Activity Diagram Sales

\section{Activity Diagram Admin}

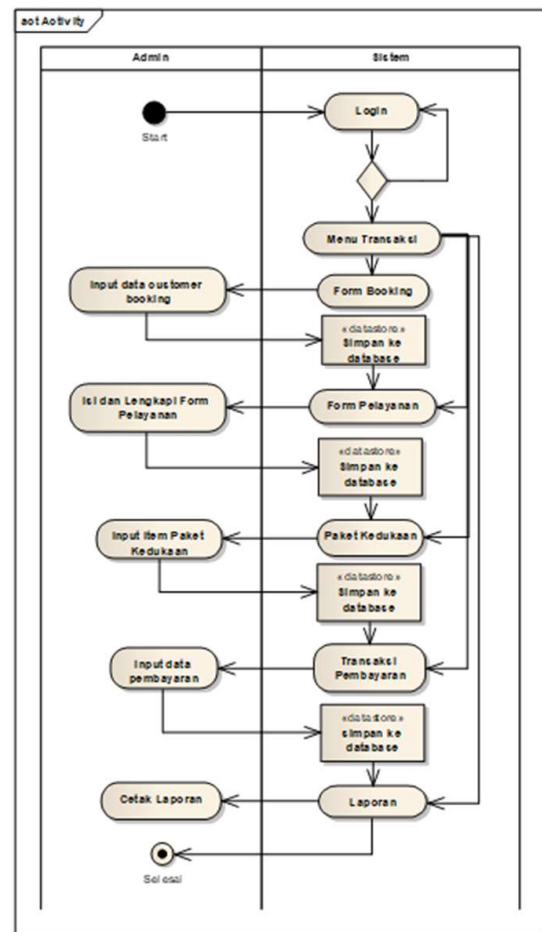

Gambar 4.3. Avtivity Diagram Admin Class Diagram

\section{Activity Diagram Sales}




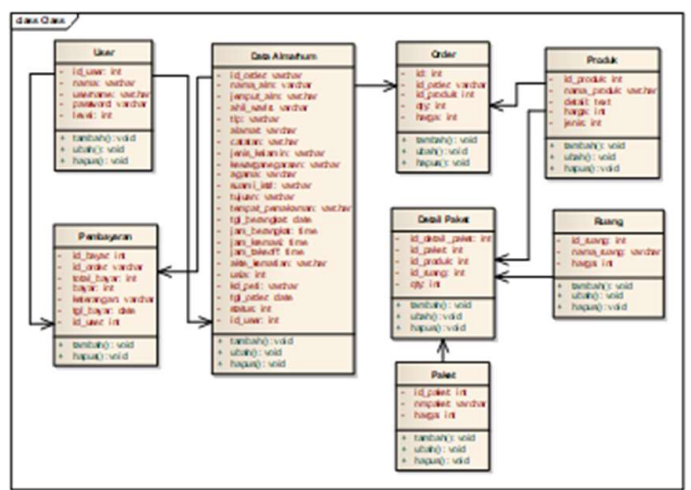

Gambar 4.4. Class Diagram

\section{Halaman Login}

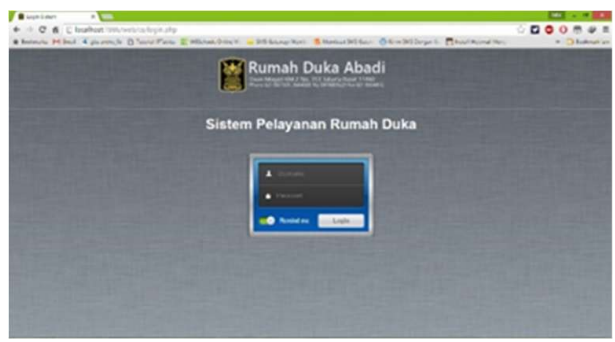

Gambar 4.5. Halaman Login Sistem

\section{Halaman Dashboard}

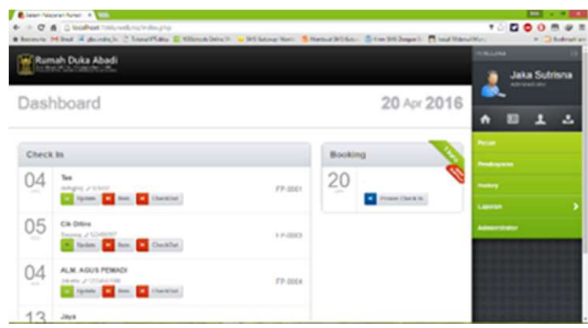

Gambar 4.6. Halaman Dashboard

\section{Halaman Booking}

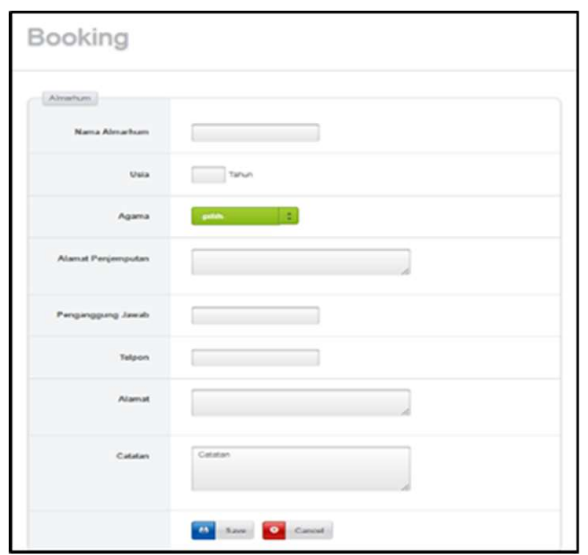

Gambar 4.7. Halaman Booking

\section{Halaman Memilih Paket Kedukaan}

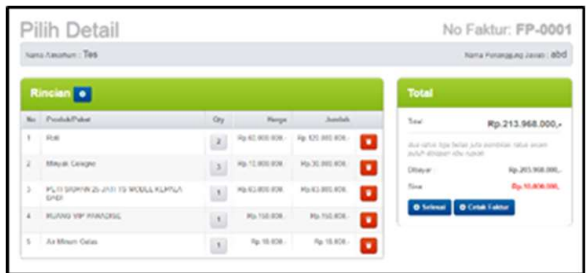

Kedukaan

Gambar 4.8. Halaman Memilih Paket

\section{Halaman Transaksi Pembayaran}

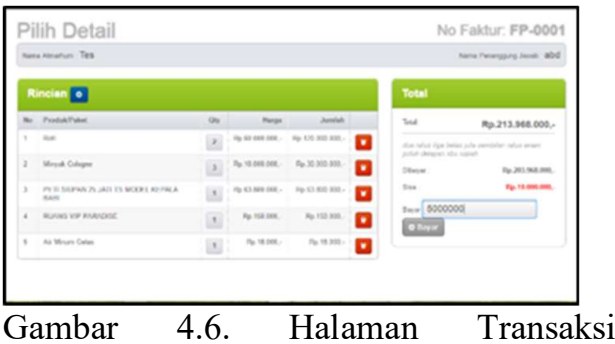

Pembayaran

\section{Halaman Cetak Faktur}

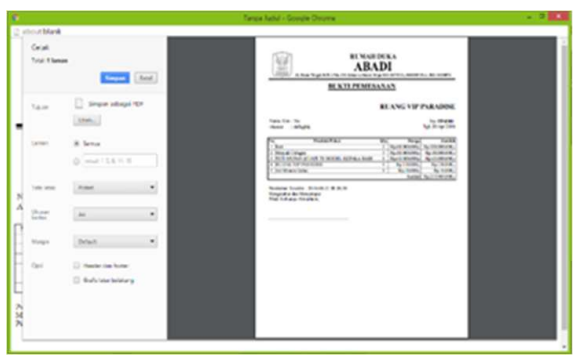

Gambar 4.7. Halaman Cetak Faktur

\section{KESIMPULAN}

Dari hasil analisis dan pembahasan, dapat disimpulkan sebagai berikut :

1) Dengan adanya Sistem Formulir Pelayanan Kedukaan Online ini maka memudahkan dalam proses pemesanan ruangan dan memudahkan dalam transaksi pembayaran, karena tidak perlu menulis secara manual mengenai bukti pembayarannya.

2) Dengan adanya Sistem Formulir Pelayanan Kedukaan Online ini dapat mengurangi terjadinya kehilangan data, karena sudah menggunakan sistem database, jadi data tersimpan di dalam komputer server dengan aman dan dapat di backup sewaktu-waktu sesuai keinginan, serta sistem ini dapat meningkatkan kinerja karyawan terutama pada divisi sales dan 
marketing dalam melakukan pelayanan terhadap pelanggan

3) Dengan adanya Sistem Formulir Pelayanan Kedukaan Online ini, dalam pembuatan laporan bisa lebih cepat dari sebelumnya yang biasanya membutuhkan waktu ber jam-jam saat melakukan rekapitulasi, sekarang hanya bisa memerlukan waktu beberapa menit saja.

\section{SARAN}

Saran yang dihasilkan untuk meningkatkan keberhasilan sistem, untuk peneliti selanjutnya adalah :

a. Diperlukan adanya pengembangan proses bisnis mengenai perhitungan laba/ rugi (keuntungan dari hasil penjualan paket/produk) untuk setiap bulannya.

b. Diharapkan adanya pengembangan lebih lanjut mengenai sistem formulir pelayanan ini supaya pelanggan juga bisa langsung order pemesanan via gadget masingmasing yaitu berupa aplikasi android.

\section{DAFTAR PUSTAKA}

Aditya, A.N. 2011. Jago PHP \& MySQL. Bekasi: Dunia Komputer.

Anwar. 2010. Panduan Menguasai PHP \& MySQL. Jakarta : Media Kita.

Christianto, V., I Made Wiryana. 2005. Pengantar Manajemen Proyek Berbasis Internet. Jakarta: PT. Elex Media Komputindo.

Fathansyah. 2012. Basis Data. Bandung: Informatika. Haryadi, Hendi. 2009. Administrasi Perkantoran untuk Manajer dan Staf. Jakarta: Visi Media.

Jogiyanto, H.M. 2008. Analisis dan Desain Sistem Informasi : Pendekatan Terstruktur Teori dan Praktek Aplikasi Bisnis. Yogyakarta: Andi Offset..

Kadir, A. 2011. Membuat Aplikasi WEB dengan PHP + Database MySQL. Yogyakarta : Andi.

Kadir, A. 2008. Pengenalan Sistem Informasi. Yogyakarta: Andi Offset.

Kusrini. 2007. Strategi Perancangan dan Pengolahan Basis Data. Yogyakarta : Andi Offset.

Oktavian, Diar Puji. 2010. Menjadi Programmer Jempolan Menggunakan PHP. Yogyakarta : Mediakom.

Rasul, Juharis. 2008. Teknologi Informasi dan Komunikasi. Jakarta: Quadra.

Sedarmayanti. 2008. Tata Kearsipan dengan Memanfaatkan Teknologi Modern. Bandung: Mandar Maju.

Sutabri, T. 2013. Konsep Sistem Informasi. Yogyakarta: Andi Publisher.

Syaukani, Muhammad. 2005. Mengelola Data pada MySQL Server Munggunakan Visual FoxPro8. Jakarta : PT. Elex Media Komputindo. 